\title{
The Role of Non-Drug Treatment Methods in the Management of Epilepsy
}

\author{
Ekaterina A. Narodova, $\mathrm{PhD}$ *; Natalia A. Shnayder, $\mathrm{PhD}, \mathrm{ScD}$; Valeria V. Narodova, $\mathrm{PhD}, \mathrm{ScD}$; \\ Diana V. Dmitrenko, PhD, ScD; Ivan P. Artyukhov, PhD, ScD \\ Krasnoyarsk State Medical University named after Prof. V.F. Voino-Yasenetsky \\ Krasnoyarsk, the Russian Federation
}

\begin{abstract}
This review is dedicated to the issue of non-pharmacological treatment of epilepsy in the adult population in Russia and other countries. A literature review was conducted using international databases for the period between 2010 and 2017. A total of 64 full-text editions were included in this review, which allowed us to reveal the basic non-pharmacological epilepsy treatment options. However, not all of these options have a sufficient evidence base, and some of them are not always safe. Particularly, methods with a low level of evidence include acupuncture and aromatherapy. Further studies are needed to explore the methods aimed at eliminating the dominant epileptic system through the development of a new, more powerful dominant system. One of the methods that can influence the pathogenesis of epilepsy is physical activity for patients with epilepsy, since epileptiform activity is reported to disappear from the EEG during exercises. The positive results of the application of music therapy are also described in the modern literature. Specifically, according to the results of some studies, the positive effect of reducing the frequency of seizures was achieved in epileptic patients who listened to music during sleep over a year. However, these studies are not numerous, so they cannot constitute a high level of evidence. Therefore, care should be exercised in applying these methods in epileptic patients. (International Journal of Biomedicine. 2018;8(1):9-14.)
\end{abstract}

Key Words: epilepsy $\bullet$ adults $\bullet$ non-pharmacological treatment $\bullet$ music therapy

\section{Introduction}

According to the world statistics, epilepsy takes the third place for overall morbidity after cardiovascular diseases and diabetes mellitus, and the third place in neurological morbidity. ${ }^{(1)}$ Therefore, epilepsy is a relevant public health problem in Russia and other countries. ${ }^{(2)}$ In recent years, considerable attention has been paid to the development and implementation of medicinal and alternative (nonpharmacological) methods for epilepsy treatment. However, current epilepsy treatment options allow achieving remission or reducing the number of seizures in only $60 \%-70 \%$ of patients. ${ }^{(3)}$ An important problem of epileptology is ensuring the safety and acceptability of the treatment as well as preventing adverse side effects (ASEs) of antiepileptic drugs (AEDs). ASEs can often

*Corresponding author: Ekaterina A. Narodova, PhD Krasnoyarsk State Medical University named after Prof. V.F. Voino-Yasenetsky, Krasnoyarsk, the Russian Federation. E-mail: nataliashnayder@gmail.com decrease patients' quality of life, thereby offsetting the positive effect of the treatment. Moreover, such ASEs as depression and anxiety (the fear of the coming seizure) may aggravate epileptic seizures. ${ }^{(4)}$ Some ASEs are associated with the effects of AEDs on the liver enzymes. These effects cause induction or inhibition of the liver enzymes, displacing other AEDs from protein linkages. These reactions increase the rate of metabolism and cause a reduction of the plasma concentration of AEDs, which may lead to difficulties in the choice of AED dosage. On average, the frequency of ASEs and complications of antiepileptic therapy remains high and varies, according to different authors, from $7 \%$ to $25 \%{ }^{(5-7)}$

Therefore, the presence of ASEs requires the immediate withdrawal of AEDs, even if drug-induced epilepsy remission is achieved. It should be noted that $40 \%$ of epileptic patients need polytherapy. This leads to an increase in the frequency of ASEs, adverse drug-drug interactions, and teratogenicity. ${ }^{(8)}$ In addition, there are difficulties in assessing the effectiveness of ASEs of a single drug. Drug-drug interactions often decrease the efficiency of antiepileptic treatment and contribute to the 
development of ASEs. ${ }^{(2,9,10)}$ Consequently, non-drug methods of epilepsy treatment should also be used, both as an additional therapy and (in some cases) as the basic therapy (for example, vagus nerve stimulation) (Table 1).

Table 1.

Non-drug methods of epilepsy treatment

\begin{tabular}{|l|l|}
\hline \multicolumn{1}{|c|}{ Non-invasive Methods } & \multicolumn{1}{c|}{ Invasive Methods } \\
\hline Physical Activity & Vagus Nerve Stimulation \\
\hline $\begin{array}{l}\text { Transcranial Magnetic } \\
\text { Stimulation }\end{array}$ & Deep Brain Stimulation \\
\hline Psychotherapy & $\begin{array}{l}\text { Percutaneous Stimulation of } \\
\text { the Trigeminal Nerve }\end{array}$ \\
\hline Music Therapy & Surgery \\
\hline Aromatherapy & \\
\hline Acupuncture & \\
\hline Referential Bioadaptation & \\
\hline
\end{tabular}

The aim of this review is to analyze studies dedicated to non-pharmacological treatment of epilepsy in adults.

\section{Materials and Methods}

We have analyzed recent full-text publications in such Russian and international databases as E-Library, PubMed, Scopus, Oxford University Press, Springer, Web of Science Core Collection. The analyzed period comprised 8 years (from 2010 to 2017). The search for publications was conducted using the following keywords: "structural epilepsy", "drugresistance", "epilepsy", "refractory epilepsy", "focal epilepsy", "intractable epilepsy", "drug-resistant focal epilepsy", and "non-drug therapy".

\section{Results and Discussion}

Patients with epilepsy experience a range of social restrictions, leading to their external and internal stigmatization. These limitations include employment problems, driving prohibition, and restriction of physical activity. However, it is a well-known fact that physical exercises lead to better functional adaptation. ${ }^{(11)}$

Patients with epilepsy who are involved in sport can receive the same benefits from physical activity as healthy people, including an increase in performance efficiency and tolerance, weight loss, and normalization of cardiovascular system functioning. Physical activity is also a critical factor in reducing the risks of diabetes, hypertension, coronary heart disease, obesity, and osteoarthritis. As for psychological advantages, the research in this field found that physically active patients have better mental health than those leading a sedentary lifestyle. ${ }^{(12-14)}$

Physical activity in early age can cause formation of a neuronal reserve, which then will be used during the life course. Consequently, physically active patients have a lower risk of developing the cognitive impairments associated with epilepsy. ${ }^{(15-17)}$
The preventive and curative effects of physical activity in cases of epilepsy can be achieved in accordance with several principles, including the principles of consistency, regularity, duration, monitoring, and personalization of the training load. Despite this, it is believed that enhanced muscular activity is accompanied with tachypnea (hyperventilation), which can initiate the seizures.

However, some authors claim that physical activity can reduce the likelihood of seizures. Usually, seizures do not occur while running, swimming, ice-skating, skiing, crossing a crowded street, or during sporting events, although this issue is disputable. On the other side, it is reported that seizures often start when patients are relaxed or sleeping. The described data accounts for the development of new dominant excitation areas in the CNS during vigorous exercises. Due to the negative induction, these areas slow down or inhibit activity in the epileptic area, thereby preventing the occurrence of seizures. It is reported that during physical exercises, seizures occur much more rarely than during relaxation. ${ }^{(1)}$ The disappearance of epileptiform activity in many patients' EEG during physical activity supports this theory. ${ }^{(18-21)}$

\section{Neurostimulation}

Vagus nerve stimulation (VNS) is one of the non-drug epileptic treatment methods. The principle of this method is in the chronic electrical stimulation of the left vagus nerve, using an implantable stimulator. ${ }^{(22)}$ The primary candidates for the application of this method are patients with drug-refractory epilepsy (DRE) who cannot get resection surgery. The main contraindications for this method are pregnancy and lactation, cardiac arrhythmia, bronchial asthma, chronic obstructive pulmonary disease, acute peptic and duodenal ulcer, vasovagal syncope and the type 1 diabetes. ${ }^{(23)}$ Against the background of VNS therapy during the period from 3 months to 3 years, a complete cessation of seizures was revealed in $4.8 \%-17.6 \%$ of patients. A decrease in the number of seizures by $50 \%$ or more was detected in $27.3 \%-47 \%$ of patients, while a decrease in the number of seizures by less than $50 \%$ was detected in $23.5 \%$ of patients. ${ }^{(24-26)}$

\section{Deep Brain Stimulation}

Deep brain stimulation is an effective therapeutic method for DRE treatment, especially for temporal lobe epilepsy. Thus, according to a randomized study, assessing the effectiveness of hippocampal stimulation in patients with temporal lobe DRE, a positive effect in the form of complete disappearance of seizures was found in $50 \%$ of patients. ${ }^{(27)}$ Other studies have shown that after 11 years of deep brain stimulation, the attacks were not registered for at least 12 months in only $13.8 \%$ of the patients. ${ }^{(28)}$

The principle of this method lies in electrode implantation into certain brain structures (target-structures); these electrodes are supplied with low voltage and high frequency electric current. Due to the impulses generated by the neurostimulator, the selected brain structures change their functions. Thus, this high frequency stimulation of the target-structures reduces the severity of the symptoms and allows reducing the amount of AEDs taken by the patients as well as bringing the patient back into society. ${ }^{(23)}$ 


\section{Transcranial Magnetic Stimulation}

Low-frequency repetitive transcranial magnetic stimulation (rTMS) leads to a decrease in cerebral cortex neuronal excitability, while high-frequency rTMS increases the excitability. ${ }^{(2)}$ The mechanisms of rTMS are related to its ability to cause long-term effects of postsynaptic inhibition in excitatory neurotransmitter systems, and a reduction in neuronal excitability through inactivation of the voltagedependent ion channels. ${ }^{(29)}$

Based on the data published till now and taking all restrictions into account, a group of European experts assigned evidentiary class $\mathrm{C}$ (probably effective) to the low-frequency mode of epileptic focus stimulation in cases where its location is in the cortex or in proximity to cortex dysplasia. ${ }^{(30)}$

\section{Percutaneous trigeminal nerve stimulation}

Percutaneous trigeminal nerve stimulation is a minimally invasive method in which the branches of the first trigeminal nerve are exposed to electricity. To implement this method in practice, a special system is used which consists of an external electric impulse generator and electro-conductive plasters. There are few studies that report the use of this method, but most of those that do consider this method to have a positive clinical effect. During preliminary clinical trials, 57\% of patients noticed a $50 \%$ or more reduction in the number of seizures.

\section{Psychotherapeutic options}

Currently, it is the practice to distinguish three fundamental categories of psychotherapeutic techniques used in epileptology: rewards/sanctions, self-control, and neurofeedback. The rewards/sanctions and self-control categories are used for selfinduced seizures and for so-called "reflective attacks" as well as for epileptic seizures that are amplified under the influence of emotional factors. Neurofeedback is a non-pharmacological method of epilepsy treatment with objective registration, amplification and feedback of physiological information to the patient. This method is based on the principle of selfidentification of one's own EEG data.

According to information from different authors, neurofeedback can lead to a great reduction in the number of seizures in $50 \%$ of cases of patients with epileptic risk factors. From this $50 \%$, in $10 \%$ of cases, it is possible to completely discontinue AEDs without the reappearance of epileptic seizures for 2-3 years and more, and in the remaining $40 \%$ $50 \%$ of cases, after the use of the neurofeedback method, it is possible to halve pharmacological treatment. ${ }^{(31)}$

There are also art-therapy options for epilepsy treatment. For example, there is an actively developing method, based on the creation of therapeutic music, to reduce the number of epileptic seizures. This method is based on the theory that epileptic seizures occur because of abnormal synchronization of the brain's electrical activity, and that the majority of them stop spontaneously. The effect of structured auditory stimuli provides non-invasive galvanic cortex stimulation, which can reduce epileptiform activity. ${ }^{(32)}$ To prove this hypothesis, researchers conducted a randomized study, which explored the effectiveness of music therapy for patients diagnosed with epilepsy. ${ }^{(33)}$ Patients were exposed to Mozart's music every night for one year. This research resulted in a $17 \%$ reduction in the number of epileptic seizures. The achieved effect remained stable during the next year. ${ }^{(34,35)}$

In another randomized study, which studied both children and adult patients with epilepsy, $85 \%$ of patients had a positive response to music therapy with an average reduction of the epileptiform activity index by $31 \%$ during listening to the music and by $24 \%$ afterwards. ${ }^{(36-44)}$

The methodology of audiogenic stimuli, proposed by Alfred Tomatis, is another art-therapy method, which is close to music therapy. ${ }^{(45)}$ However, in clinical practice, we meet with an increase in the number of epileptic seizures by $50 \%$ $60 \%$ after the use of this method. As a result, currently, the effectiveness of this method remains debatable.

Aromatherapy can be useful (for achieving a state of relaxation) as a component of epilepsy behavioral treatment. However, its use is more justified for the treatment of conditions accompanying epilepsy, such as anxiety and depression. In the application of aromatherapy for patients with epilepsy, camphora, sage, and rosemary should be avoided because these substances are known to aggravate patients' condition and increase the number of epileptic seizures. ${ }^{(10)}$

In the Asian-Pacific region, acupuncture is actively used as a non-pharmacological method of epilepsy treatment. There are data on the use of acupuncture for patients with strokes in order to avoid post-stroke epilepsy. S.Weng and colleagues showed that patients with strokes who received acupuncture had significantly less probability of post-stroke epilepsy, compared to those who did not receive such treatment $(\mathrm{P}<0.0001)$. However, defensive effects associated with acupuncture need further exploration. ${ }^{(46)}$

Some authors report neuroprotective, antiinflammatory and neurotrophic effects of acupuncture and electroacupuncture. These effects are explained by the amplification of recurrent inhibition of the brain cortex and hippocampus with the liberation of different neurotransmitters, including gamma-aminobutyric acid and serotonin. However, due to the lack of controlled clinical trials, those methods cannot be recommended as reliably effective and safe in epileptology. ${ }^{(47)}$

\section{Conclusion}

Based on the results of our literature review, it can be stated that an adequate number of studies of the analyzed period are dedicated to non-pharmacological epilepsy treatment. Methods with both proved clinical effectiveness and low reliable treatment options were found in the studied literature. Most of the authors emphasize a positive influence of physical activity on epileptic patients, including prevention of epileptic seizures. Besides, physical activity is reported to have a positive influence on patients' psychic function, preventing cognitive disorders. However, up until now, physical exercises as an additional therapy are not included in any treatment program for patients with epilepsy. The analysis of the literature showed that this lack of inclusion is due to a current concern among neurologists and epileptologists about the 
occurrence of epileptic seizures in a state of hyperventilation. Those concerns are not unfounded, because hyperventilation can provoke epileptic seizures in a certain group of patients with epilepsy. As a result, it is reasonable not to ban physical activity for all epileptic patients, but to limit its intensity for the group of patients in whom hyperventilation can provoke epileptic seizures. Meanwhile, the fact is reported that during physical exercising, epileptic patients' EEGs show reduced epileptiform activity. Finally, regarding music therapy, there are studies that suggest it has a positive effect, but the issue is still under-investigated.

All the options for non-pharmacological epilepsy treatment represented in the present review are based on the classical theory of G.N.Kryzhanivsky about the creation and destruction of pathological systems. ${ }^{(48)}$ The author noted that in early stages of the disease, the elimination of the pathological determinant leads to liquidation of the pathological system.

In late stages, the fixation of a pathological system leads to chronization of the pathological process and corresponding neural disorders. The battle with pathological systems, especially with those with complicated and matured forms, is hard and is not always effective. It requires a complex pathogenetic therapy, focused on elimination of the pathological determinant (for example, the elimination of epileptic focus) and normalization of other links of the pathological system. Activation of the anti-epileptic system, amplification of overall control and other genetic mechanisms are important as well. It is also known that there is a constant countdown in living systems, on which homeostasis is based. ${ }^{(49)}$

According to the theory of V.A.Rudnev ${ }^{(50)}$ so-called "internal time" is a genetic core of any motor activity, having characteristics of both populations and individuals. Internal time is expressed as an individual rhythm. Many studies explore individual rhythm, its "maturation" in late ontogenesis, as well as its breaking in different cases of neural disorders. ${ }^{(51)}$ Individual rhythm is a reflection of the harmony of the brain's work, and its breaking is a sign of disintegration in the brain's work. Since it is an established fact that in cases of epilepsy a pathological activation of the brain's neurons occurs, which is a stress for the central neural system, it is possible that the occurrence of an epileptic system can change a patient's individual rhythm.

Consequently, research on individual rhythm changes in patients with symptomatic post-surgery epilepsy, and comparison of these changes with the individual rhythm indicators of healthy persons, can help to create a new dominant in the absence of pathological focus and reset the remaining epileptic system links, imposing the mode of operation closest to the physiological one, and activate the anti-epileptic system. There is also a concept that states "seizures lead to seizures." First proposed by doctor William Gowers (1881) and reflecting the concept of epilepsy as a progressing disease, ${ }^{(52)}$ this concept remains relevant. Therefore, taking into account the prevalence rate of epilepsy and lack of desired effects of pharmacological therapy, the development of new non-pharmacological treatment options, dedicated to creation of a new dominant in the human brain to suppress the formation and activity of a pathological epileptic system, becomes relevant.

\section{Competing interests} interests.

The authors declare that they have no competing

\section{References}

1. Avakyan GN. [Epidemiology of epilepsy and optimization of drug therapy for focal epilepsy]. Epilepsy and Paroxyzmal Conditions. 2014;6(5):3-5. [Article in Russian].

2. Karlov VA. [Epilepsy in children and adults, women and men: a guide for doctors]. Moscow: Medicine; 2010. [In Russian].

3. Melikyan EG, Gekht AB. [Life quality in epileptic patients]. Lechebnoe delo. 2011;(1):4-8. [In Russian]

4. Kalinin VV. [Correction of affective and cognitive disorders in epileptic patients and the value of lamotrigine]. Neurology, Neuropsychiatry, Psychosomatics. 2013;5(2):7883. [Article in Russian].

5. Voronkova KV, Pylaeva OA, Kosyakova ES, Mazalskaya OV, Golosnaya GS, Provatorova MA, et al. [Modern principles of epilepsy therapy]. Zh Nevrol Psikhiatr im S.S. Korsakova. 2010;(6):24-36. [Article in Russian].

6. Zenkov LR. [Clinical epileptology]. Moscow: MIA; 2010. [In Russian].

7. Bochanova E. [Pharmacogenetics of antiepileptic drugs (literature review)]. Good Clinical Practice. 2017;(1):51-55. [Article in Russian].

8. Dmitrenko DV, Shnaider NA, Strotskaya IG, Kichkaylo AS, Zobova SN. [Mechanisms of valproate-induced teratogenesis]. Neurology, Neuropsychiatry, Psychosomatics. 2017;9(1S):8996. doi:10.14412/2074-2711-2017-1S-89-96. [Article in Russian].

9. Kwan P, Arzimanoglou A, Berg AT, Brodie MJ, Allen Hauser W, Mathern G, et al. Definition of drug resistant epilepsy: consensus proposal by the ad hoc Task Force of the ILAE Commission on Therapeutic Strategies. Epilepsia. 2010;51(6):1069-77. doi: 10.1111/j.1528-1167.2009.02397.x. 10. Karpova VI, Krushinskaya NS, Mukhin KYu. [Epilepsy: history, diagnosis, practice, treatment, advice to patients]. Moscow: System solutions; 2011. [In Russian]

11. Astashenko OI. [Encyclopedia of therapeutic movements in various diseases: joints, back and spine, gynecological and urological, heart and blood vessels, liver and gastrointestinal tract]. St. Petersburg: Vector; 2009. [In Russian]

12. Arida RM, Cavalheiro EA, Scorza FA. From depressive symptoms to depression in people with epilepsy: contribution of physical exercise to improve this picture. Epilepsy Res. 2012;99(1-2):1-13. doi: 10.1016/j.eplepsyres.2011.10.012.

13. Sitnikov IYu, Mikhailova NV, Savinov SV, Abedimova RA, Akchurina YaE, Bondareva IV, et al. [Physical load and epilepsy]. Neurosurgery and Neurology of Kazakhstan. 2015;41(4):13-17. [Article in Russian].

14. Nass RD, Meiling S, Andrié RP, Elger CE, Surges R. Laboratory markers of cardiac and metabolic complications after generalized tonic-clonic seizures. BMC Neurol. 2017;17(1):187. doi: 10.1186/s12883-017-0965-4.

15. Tutkun E, Ayyildiz M, Agar E. Short-duration swimming exercise decreases penicillin-induced epileptiform ECoG activity in rats. Acta Neurobiol Exp (Wars). 2010;70(4):382-9. 16. Middleton LE, Barnes DE, Lui LY, Yaffe K. Physical activity over the life course and its association with cognitive 
performance and impairment in old age. J Am Geriatr Soc. 2010;58(7):1322-6. doi: 10.1111/j.1532-5415.2010.02903.x. 17. Gomes da Silva S, de Almeida AA, Silva Araújo BH, Scorza FA, Cavalheiro EA, AridaRM. Early physical exercise and seizure susceptibility later in life. Int J Dev Neurosci. 2011;29(8):861-5. doi: 10.1016/j.ijdevneu.2011.07.011.

18. Arida RM, Scorza FA, Cavalheiro EA. Favorable effects of physical activity for recovery in temporal lobe epilepsy. Epilepsia. 2010;51 Suppl 3:76-9. doi: 10.1111/j.15281167.2010.02615.x.

19. Arida RM, Scorza FA, Gomes da Silva S, Schachter SC, Cavalheiro EA. The potential role of physical exercise in the treatment of epilepsy. Epilepsy Behav. 2010;17(4):432-5. doi: 10.1016/j.yebeh.2010.01.013.

20. Vancini RL, de Lira CA, Scorza FA, de Albuquerque $\mathrm{M}$, Sousa BS, de Lima $\mathrm{C}$, et al. Cardiorespiratory and electroencephalographic responses to exhaustive acute physical exercise in people with temporal lobe epilepsy. Epilepsy Behav. 2010;19(3):504-8. doi: 10.1016/j.yebeh.2010.09.007.

21. de Lima C, Vancini RL, Arida RM, Guilhoto LM, de Mello MT, Barreto AT, et al. Physiological and electroencephalographic responses to acute exhaustive physical exercise in people with juvenile myoclonic epilepsy. Epilepsy Behav. 2011;22(4):718-22. doi: 10.1016/j. yebeh.2011.08.033.

22. Khachatryan VA, Mamatkhanov MR, Lebedev KE. [Vagostimulation in the system of surgical treatment of epilepsy]. Pediatric Neurosurgery and Neurology. 2012;(23):152-161. [Article in Russian].

23. Balabanova AI, Bavdurnuy AA, Bolba MV, Belova EV, Rakhmanina OA, Muravjov SA. [Life style and non-medication treatment methods of epilepsy]. Medical Science and Education of Ural. 2015;16(2-1):139-145. [Article in Russian].

24. Vaiman M. [Treatment of epilepsy with vagus nerve stimulation: the Israeli experience]. 2013. Available at: http:// www.medines.net/cms/28-статьи/143 [Article in Russian].

25. Lipatova LV, Skoromets TA, Gromov SA, Tabulina SD, Vtorov AV, Bondareva MM, et al. [Experience of using vagus nerve stimulation to treat drug resistant epilepsy]. Neurology, Neuropsychiatry, Psychosomatics. 2014;6(1Suppl):18-21. doi: 10.14412/2074-2711-2014-1S-18-21. [Article in Russian].

26. Sufianov AA, Orlov AS, Matveev EI, Lebedeva DI. [Experience with use of chronic neurostimulation of vagus nerve in treatment of pharmacoresistant epilepsy]. Epilepsy and Paroxyzmal Conditions. 2012;4(3):48-49. [Article in Russian]. 27. Cukiert A, Cukiert CM, Burattini JA, Mariani PP, Bezerra DF. Seizure outcome after hippocampal deep brain stimulation in patients with refractory temporal lobe epilepsy: A prospective, controlled, randomized, double-blind study. Epilepsia. 2017;58(10):1728-1733. doi: 10.1111/epi.13860 28. Kim SH, Lim SC, Kim J, Son BC, Lee KJ, Shon YM. Longterm follow-up of anterior thalamic deep brain stimulation in epilepsy: A 11-year, single center experience. Seizure. 2017;52:154-161. doi: 10.1016/j.seizure.2017.10.009.

29. Funke K, Ben-Ali A. Modulation of cortical inhibition by rTMS - findings obtained from animal models. J Physiol. 2011;589(Pt 18):4423-4435. doi: 10.1113/ jphysiol.2011.206573.

30. Hsu WY, Cheng CH, Lin MW, Shih YH, Liao KK, Lin YY. Antiepileptic effects of low frequency repetitive transcranial magnetic stimulation: A meta-analysis. Epilepsy Res. 2011;96(3):231-240. doi: 10.1016/j.eplepsyres.2011.06.002.

31. Sterman MB, Egner T. Foundation and practice of neurofeedback for the treatment of epilepsy. Appl Psychophysiol Biofeedback. 2006;31(1):21-35.

32. Fisher RS. Therapeutic devices for epilepsy. Ann Neurol. 2012;71(2): 157-68. doi: 10.1002/ana.22621.

33. Bodner M, Turner RP, Schwacke J, Bowers C, Norment C. Reduction of seizure occurrence from exposure to auditory stimulation in individuals with neurological handicaps: a randomized controlled trial. PLoS One. 2012;7(10): e45303. doi: 10.1371/journal.pone.0045303.

34. Mehndiratta P, Sajatovic M. Treatments for patients with comorbid epilepsy and depression: a systematic literature review. Epilepsy Behav. 2013;28(1):36-40. doi: 10.1016/j. yebeh.2013.03.029.

35. Schmidt D, Sillanpaa M. Evidence-based review on the natural history of the epilepsies. Curr Opin Neurol. 2012;25(2):159-63. doi:10.1097/WCO. 0b013e3283507e73.

36. Dastgheib SS, Layegh P, Sadeghi R, Foroughipur M, Shoeibi A, Gorji A. The effects of Mozart's music on interictal activity in epileptic patients: systematic review and meta-analysis of the literature. Curr Neurol Neurosci Rep. 2014;14(1):420. doi: 10.1007/s11910-013-0420-x.

37. Cardamone L, Salzberg MR, O'Brien TJ, Jones NC. Antidepressant therapy in epilepsy: can treating the comorbidities affect the underlying disorder? Br J Pharmacol. 2013;168(7):1531-54. doi: 10.1111/bph.12052.

38. Bozzi Y, Borrelli E. The role of dopamine signaling in epileptogenesis. Front Cell Neurosci. 2013;7:157. doi: 10.3389/fncel.2013.00157.

39. Rocha L, Alonso-Vanegas M, Villeda-Hernandez J, Mujica M, Cisneros- Franco JM, Lopez-Gomez M, et al. Dopamine abnormalities in the neocortex of patients with temporal lobe epilepsy. Neurobiol Dis. 2012;45(1):499-507. doi: 10.1016/j.nbd.2011.09.006.

40. Raglio A, Farina E, Giovagnoli AR. Can music therapy alleviate psychological, cognitive, and behavioral impairment in epilepsy? Epilepsy Behav. 2014;31:7-8. doi:10.1016/j. yebeh.2013.10.008

41. Modi AC, Rausch JR, Glauser TA. Early pediatric antiepileptic drug nonadherence is related to lower long-term seizure freedom. Neurology. 2014;82(8):671-3. doi: 10.1212/ WNL.0000000000000147.

42. Tavakoli F, Hoseini SE, Mokhtari M, Vahdati A, Razmi $\mathrm{N}$, Vessal M. Role of music in morphine rewarding effects in mice using conditioned place preference method. Neuro Endocrinol Lett. 2012;33(7):709-12.

43. Lin LC, Juan CT, Chang HW, Chiang CT, Wei RC, Lee MW, et al. Mozart K.448 attenuates spontaneous absence seizure and related high-voltage rhythmic spike discharges in Long Evans rats. Epilepsy Res. 2013;104(3):234-40. doi: 10.1016/j.eplepsyres.2012.11.005.

44. Tasset I, Quero I, García-Mayórgaz ÁD, del Río MC, Túnez I, Montilla P. Changes caused by haloperidol are blocked by music in Wistar rat. J Physiol Biochem. 2012;68(2):175-9. doi: 10.1007/s13105-011-0129-8.

45. Coppola G, Toro A, Operto FF, Ferrarioli G, Pisano $\mathrm{S}$, Viggiano A, et al. Mozart's music in children with drugrefractory epileptic encephalopathies. Epilepsy Behav. 2015;50:18-22. doi: 10.1016/j.yebeh.2015.05.038.

46. Weng SW, Liao CC, Yeh CC, Chen TL, Lane HL, Lin JG, et al. Risk of epilepsy in stroke patients receiving acupuncture treatment: a nationwide retrospective matchedcohort study. BMJ Open. 2016;6(7):e010539. doi: 10.1136/ bmjopen-2015-010539. 
47. Yi PL, Jou SB, Wu YJ, Chang FC. Manipulation of Epileptiform Electrocorticograms (ECoGs) and Sleep in Rats and Mice by Acupuncture. J Vis Exp. 2016;(118). doi: $10.3791 / 54896$.

48. Kryzhanovskii GN. [Fundamentals of general pathophysiology]. Moscow: Medical News Agency; 2011. [In Russian].

49. Moiseeva NI. [Some methodological aspects of the study of the concept of time in biology]. In: Bekhtereva NP, ed. [Methodological questions of the time of theoretical medicine]. Leningrad: Medicine;1975:87-117. [In Russian].

50. Rudnev VA. [Functional diagnosis and recovery of voluntary movements in the pathology of the central nervous system]. Krasnoyarsk: Publishing house of Krasnoyarsk University; 1982. [In Russian].

51. Narodova EA, Prokopenko SV, Narodova VV, Narodov AA. [Rehabilitation of the patients with complex motor aphasia during the ischemic insult]. Vestnik Novich Medicinskich Technologii. 2012;1. Available from: http://medtsu.tula.ru/VNMT/Bulletin/E2012-1/3938.pdf. [Article in Russian].

52. Kwan P, Schachter SC, Brodie MJ. Drug-resistant epilepsy. N Engl J Med. 2011;365(10):919-26. doi: 10.1056/ NEJMra1004418. 